\title{
An Enhanced Online Shopping System using M-Wallet
}

\author{
Nwachukwu C.B. \\ Department of Computer Science, \\ Ignatius Ajuru University of Education, \\ Rivers State, Nigeria
}

\author{
F.E. Onuodu \\ Department of Computer Science, \\ University of Port-Harcourt, \\ Rivers State Nigeria
}

\begin{abstract}
E-commerce is a generally accepted business paradigm in this era of technological evolution. This paradigm fosters the sale, purchase or transfer of funds over an electronic network, basically over the internet. The development of e-commerce gave rise to new terms such as e-payment etc. E-payment is the general method adopted for payments of the e-commerce transaction. There are several e-commerce systems currently available, however these platform has a major issue of lack of secure and efficient payment platform for easy transaction without any glitch. Some of the payment platforms in existence have been hijacked by fraudsters and used to dupe customers who dare to carry out e-payment using their channels. In this work, an enhanced online shopping using M-Wallet has been developed and implemented. The system used encryption algorithms such as MD-5 algorithm to guarantee confidentiality of user's information. The Structured System Analysis and Design Methodology (SSADM) was adopted in this approach. The system was implemented using Hypertext Preprocessor (PHP) and MySQL as database. The proposed system had a total performance score of $40 \%$ based on certain parameters, while the existing system had a performance score of $26 \%$. This system will be beneficial to e-vendors, e-online shoppers and the research community.
\end{abstract}

\section{Keywords}

E-shopping, M-Wallet, Digital Payment, Digital Trading,

\section{INTRODUCTION}

E-commerce is a concept that has gained tremendous recognition in recent years. It has become a generally accepted business paradigm in this era of technological evolution. This paradigm fosters the sale, purchase or transfer of funds over an electronic network, basically over the internet [1]. E-commerce is in fact the new norm, especially in the sale and purchase of goods, i.e. online shopping.

Most prominent businesses like Amazon, Jumia, Wish, Konga, etc. do not have physical stores where people can walk in to make purchases of their desired products, however the internet is the shop or store of those businesses. All the products are displayed in well organized and attractive layouts for the perusal of potential customers who may either end up initiating a purchase transaction or merely admire the products displayed.

This innovation has helped to solve so many problems such as theft of products by the buyers and great losses on the side of the vendors. The safety concerns of carrying physical cash around to pay for purchased products is also eliminated with the use of these e-commerce platforms, and so many other benefits. One can now shop from the comfort of their homes and have it delivered to their doorsteps without breaking a sweat. Also one can purchase things from another state, region or even country and have them delivered. This has indeed made shopping a lot of fun.
The development of e-commerce gave rise to new terms such as e-payment etc. E-payment is the general method adopted for payments of the e-commerce transaction. A very common type of e-payment is the mobile wallet often referred to as M-wallet, which just like the physical wallet holds the information of the owner's financial details such as credit card details or other payment card details and allows the user to pay for future transactions with merchants that are listed with the mobile wallet service provider. The mobile wallet runs mostly on mobile devices and is a developed in form of an application.

\subsection{Statement of the Problem}

Since the emergence of the e-commerce concepts, various business and business owners have adopted and subscribed to this new way of doing business. However, this platform has a major issue of lack of secure and efficient payment platform for easy transaction without any glitch. Some of the payment platforms in existence have been hijacked by fraudsters and used to dupe customers who dare to carry out e-payment using their channels.

Another problem in the online shopping sect is fraud that is associated with the delivery of a totally different product from the one advertised on the e-commerce page.

\subsection{Aim and Objectives}

The aim of this study is to develop a secure online shopping platform using $\mathrm{M}$-wallet payment platform. The specific objectives are to:

i. Design an online shopping system for fashion products.

ii. Simulate a secure M-wallet payment platform for shopping in an online store.

iii. Implement using Hypertext preprocessor, JavaScript as programming languages and MySQL as database.

iv. Evaluate our results with other existing system performance.

\section{LITERATURE REVIEW}

In this section we will give a detailed description of the basic concepts behind this research.

\subsection{The Concept of E-Commerce}

E-commerce is a form of electronic trade (e-trade) in which purchase of products and services can been done over the internet. Nowadays everything can be bought online in a term called "ordering". Products ranging from perishables, electronics, furniture, properties etc. can now be purchased without visiting any physical store or office but rather via the online shopping platforms that run on the internet. Practically everything available in the conventional market can also available online. There are so many advantages of this form of trading, however here are few of them: 
i. Time saving: this mode of trading has reduced to the barest minimum the amount of time that would have been taken to visit a physical store, negotiate prices, pay for the products and get back home.

ii. Secure shopping: robberies of both the vendors and the customers are removed using this platform.

iii. Ease of transaction: everything is carried out virtually without any hassle or breaking of sweat.

iv. Product tracking: a user can check for the availability of a particular product, compare prices among vendors and make the purchase anytime and from anywhere.

v. Customers can also purchase products from foreign countries without travelling there physically.

vi. Products can be delivered to any location within the shortest possible time provided the location is accessible (in terms of good road networks).

Some prominent online shopping platforms available in Nigeria include: Jumia, Konga, JiJi, Amazon, Wish, Alibaba Express etc. These platforms have gained reasonable recognition and acceptance by Nigerians as they has added flavor to the shopping experience of Nigerians.

\section{i. Data Management in Online Shopping}

The online shopping platforms handle data such as user details and orders. The data objects of the user include: name of user, location of user, email, role, etc. while the order details include: products in the user's cart, products paid for, details of products, price, quantity, description, image, category, product Id etc.

\subsection{Electronic Payment}

Electronic Payment is the process of paying for a product or service over a digital channel rather than the conventional physical payment method. Electronic payment is a common feature of the e-commerce industry. It provides for easier and safer payment options for buyers and sellers. E-payment is performed using digital wallets.

\subsubsection{Security Properties of Electronic Payment}

If an electronic payment platform lacks protection and security, i.e. user information security and security of the monetary transaction, it clearly defies its essence. Confidentiality, data integrity, authentication and non-repudiation compulsory properties that a secure e-payment platform must possess in order to be classified as safe. For users to guarantee their approval, Trust must be established from the e-payment platform's side. Other properties include robustness, availability and efficiency. These properties are illustrated in fig. 1.

Since the e-commerce platforms are available 24/7, the epayment platforms must also act in the same vein.

\subsubsection{A Digital Wallet}

According to Wikipedia [2], A digital wallet also referred to as an e-wallet can be defined as "an electronic device, an online service or software program that allows a person/party that make electronic transactions with another person or party exchanging digital currency units for goods and services. Mobile wallet is a very prominent type of digital wallet.

\subsubsection{A Mobile Wallet}

Mobile Wallet is an application stored in mobile phones providing to subscribers the possibility to perform various mobile financial transactions. It is ranked as one of the best inventions of the $21^{\text {st }}$ century. They are also called digital wallets. According to Zhao and Muftic [3], the concept of secure m-wallets involves several stakeholders such as mobile network operators, banks, credit card processors, small merchants, Web merchants, and the most important, client users. Payment done using this tool is faster, more convenient, safer and more cost effective than the conventional payment methods. Mobile wallet is also recognized for its innovative benefits such as customization and instant communication [4]. This electronic payment tool continues to gain gross recognition despite the fleet of electronic payment platforms developed every day.

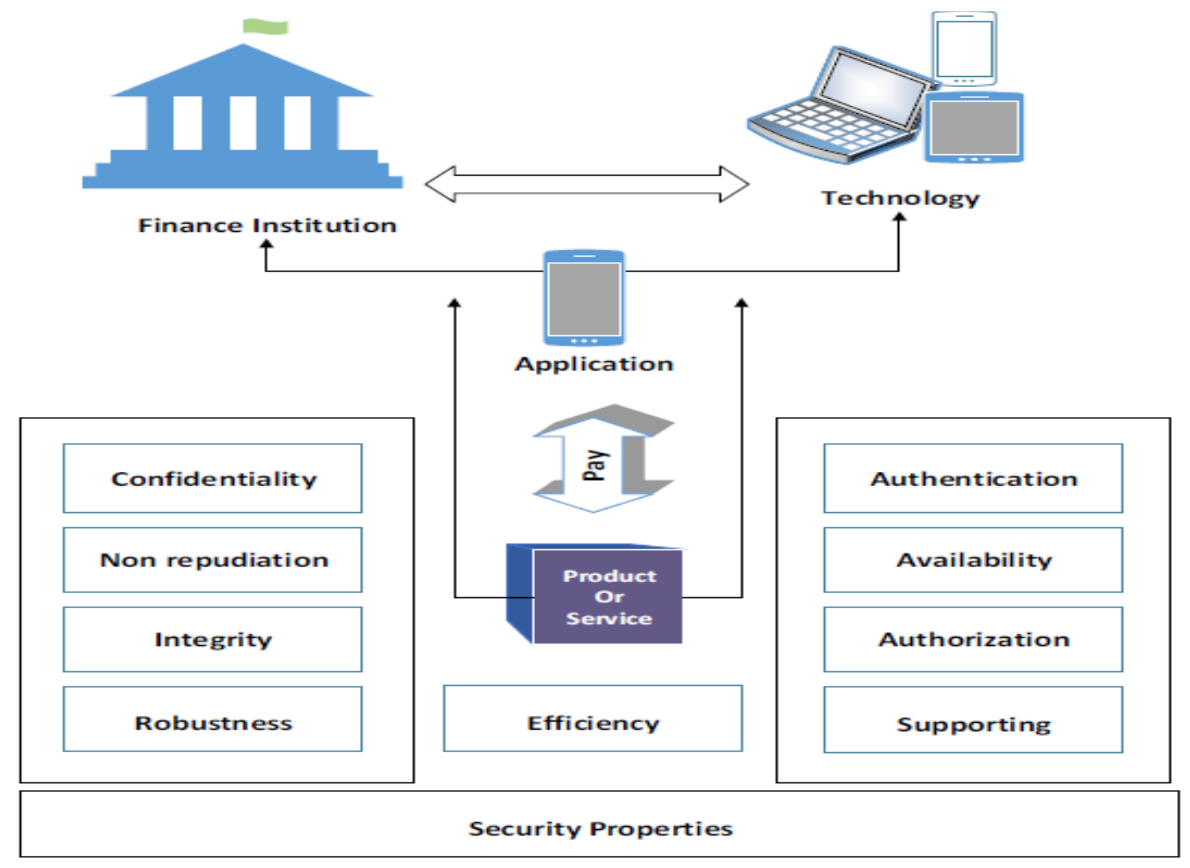

Figure 1: Security properties of E-Payment Platforms (Hassan et al [5])

For those in the developed countries who do not have bank accounts (the unbanked persons), m-wallet proves to be a very effective payment tool for their various transactions in a safe and easy light. The telecom and the banking markets are the primary markets for m-wallet. While the web service providers and the financial service providers form the secondary market. 
The most common examples of m-wallet applications include PayPal, Google Pay, Samsung Pay, Venmo and Zelle. In Nigeria, PayPal is the most common m-wallet application used to purchase products from online vendors such as Jumia, Konga, JiJi, etc.

M-wallet satisfies the two requirements of an electronic payment platform which are authorization and Settlement.

\subsubsection{Authorization}

This process verifies that the payment tool is active and that the user has sufficient balance to make the transaction.

\subsubsection{Settlement}

This is the actual payment process where the customer's payment account is charged and the money is transferred from the user's account to the vendors account.

\subsection{Related Work}

Zao and Muftic [3] design and implementation of a mobile transactions client system a secure UICC mobile wallet. The Mobile wallet was stored and run on a Javacard SIM chip called UICC module. Several Javacard applets were contained in the

Wallet for different financial transactions such as mobile banking, mobile ticketing, loans etc. Over-the-air (OTA) transactions were supported by the mobile wallet based on SMS, GPRS, or mobile internet protocols. The OTA and OTC managed users, messages stored in the Wallet.

Isaac et al [6] proposed an adaptive e-commerce application using web framework technology and machine learning. The system was implemented using Web2py Python Model-ViewController (MVC). They provided 2-level solution which included basic implementation using cookies functionality, and advanced implementation based on the integration of machine learning algorithms. However, they could not achieve trustability in the application.

Bakar et al [7] presented an e-wallet transactional framework for digital economy. The procedure involved in the transactional process was explained in the study starting from registration of user and service provider, payment composition and profit generation for the business model of e-wallet provider. An ease analysis to increase awareness about e-wallet and its transaction was also provided in the study. However, they could not implement their framework with a programming language.

Zheng et al [8] proposed an intelligent recommendation system based on customer segmentation. A methodology for intelligent recommendations in e-commerce was developed and a recommender system was used to implement the methodology. They ranked the loyalty of customers using Fuzzy c-means (FCM) clustering approach. ANN and FCM was also used to select customers who would likely buy recommended products. However, they could not provide the performance analysis result of their proposed model.

Zulaikha et al [9] proposed an integrated management system for online shopping portals. They carried out a quantitative research in which 183 persons who use the online shopping platform consisting of $56 \%$ female and $44 \%$ males. The results from the analysis revealed that men are more supportive of the online platform than women (whose level of acceptance is affected by the price of the product).
Nafi et al [10] proposed a fuzzy logic based certain trust model for e-commerce. Their model could be used to easily distinguish between companies and other elements of trust model will also be considered by the clients rating for the companies and for different transactions. They demonstrated that although fuzzy works with uncertainties, proposed model works with some certain values. However, they could not develop an e-commerce platform using their proposed trust model.

Junadi and Sfrenraianto [11] proposed a model of factors influencing consumer's intention to use e-payment system in Indonesia. The model was developed by integrating into the model the unified theory of acceptance and use of technology (UTAUT) with culture and perceived security so as to define the important factors that influence e-payment. However, they were unable to development a practical e-payment system to test their theory. However, they did not implement practically to demonstrate their claims.

$\mathrm{Wu}$ and $\mathrm{Wu}$ [12] proposed an agent-based fuzzy recommendation system using shoppers' preference for ecommerce application.To examine the performance and adaptability of the system, we selected a Nokia N97 cell phone as the target product for shopping. Then we ran the system on two different sets of policies, which reflect two different shopping preferences, to compare the final recommendation lists and compare the recommendation list with the user's own decision.However, e-payment platform was not integrated in their design.

Vatrapu[13] presented design and implementation of ecommerce site for online shopping.

Their system providedan efficient way of adding almost all the features of the online shopping. They implemented their system using HTML, CSS, PHP, JS and Sublime text (front end) and Xampp Server was used to store the database (back end). The website contained a large memory of storing all the goods in the shop and also keeping record, it was considered highly effective and accurate.

Effiong [14] proposed the design and implementation of an online shopping system. The primary goal of the system was to demonstrate the interactive feature of an e-shopping website which leads to better sales online. They reviewed related literatures about e-shopping to gain background on the topic. The system was implemented with VB.Net programming language. The designed system was a prototype e-shopping system. However, they lacked vital information about the concept of shopping system which led to lapses in the study.

Wei and Zhang [15] proposed design and implementation of online shopping system based on $\mathrm{B} / \mathrm{S}$ (Business/Server) structure. Java and JSP were used to implement the system and MySQL was used as the database. Network of online shopping system was integrated through the MVC (Model, View and Controller) framework. This framework completed the control layer management and processed access to data. However, payment method(s) of this system was unspecified.

Amca and Celebi [16] presented design and application of mobile payment system with embedded systems and service oriented architecture. They investigated use of mobile communication devices which were used to satisfy managerial and financial requirements. They presented the variable transaction number (VTN) for each transaction. According to the system evaluation, they discovered that the requirement for the development of this technology was cost effective. However, they could not demonstrate the results gotten from their system. 
Karim et al [17] presented factors influencing the use of wallet as a payment methods among Malaysian young adults. They collected a total of 33o data from e-wallet users from the Klang area. The partial least square structural equation modelling (PLS-SEM) for the analysis of the data collected. They applied a two-step approach such as measurement model for indicator loadings, convergent validity, reliability and structural model for path analysis the findings from their study exposed that seeming usefulness, apparent ease of use and privacy and security have positive and significant relationship with behavioral intention to use e-wallet.

Pramsane [18] proposed design and implementation of online shopping center. Their system provided a simple web store creation tool for shop owners to manage their stores using the content management system. The user-friendly approach helped naïve web users to create and manage their stores in the market place. The market place was designed by splitting products into various categories. Also, shoppers could see the products easily in product groups together with their sub categories.

Unadkat and Barot [19] presented a survey paper on fuzzy logic based recommender system. They presented a categorical review of the field of recommender systems and describes the state-ofthe-art of the recommendation methods which were classified into four categories: Content based Collaborative, Demographic and Hybrid systems. They used fuzzy logic and Markov chain algorithm to develop recommender system.

Hassan et al [20] presented a review on electronic payment system. 131 research materials were collected and reviewed between 2010 and 2020 using qualitative method. They aimed at answering the questions on the security issues of regarding the use of e-payment and security properties needed to guarantee secure e-payment.Their results showed that due to the increasing use of e-payment platform, security measures such as availability, authorization, integrity, non-repudiation, authentication, and confidentiality must be put in place to guarantee safe use.Onuodu and Ajaba [21] proposed an organized recommender system for Nigerian fashion using machine learning. The filtering techniques was classified into two categories viz. Collaborative Filtering and Content Based Filtering. Their Recommender system aimed to predict users' ratings on items and suggest certain items to users that they were most likely to be interested in. However, their scope was restricted to just recommendation as they could not use m-wallet or any other digital platform to make online purchases.

\section{METHODOLOGY}

Structured System Analysis and Design Methodology (SSADM) was adopted in this approach. SSADM is a systems approach to the analysis and design of information systems. The method of how SSADM was applied to the Proposed System Design stages.

\subsection{System Design Stages}

\subsubsection{Stage One}

Analyzing Existing ways deployed to tackle the issue:

There was in-depth analysis on current performance of the Existing System in Recommending reliable information to users.

\subsubsection{Stage Two}

Existing System Performance and Identification of Anomalies:
This phase involved studying result performance of the Existing System in order to spot any anomaly that should be corrected.

\subsubsection{Stage Three}

This phase involves the adoption of the most efficient result that tackles the mentioned issue due to the outcome of the comparison between the Existing and Proposed Systems.

\subsection{Data Management}

Data was generated using the various input forms in the implementation. The data of the credit card and transaction using M-wallet platform were stored in a structured form in the MySQL database which ran on the XAMPP local servers. The data about the products on the online shop were also stored in the database including their details (Prices, Categories, and Orders etc.).

\subsection{Architecture of the Existing System}

The existing system was developed by Onuodu and Ajaba [21]. They proposed an organized recommender system for Nigerian fashion using machine learning. The filtering techniques was classified into two categories viz. Collaborative Filtering and Content Based Filtering. Their Recommender system aimed to predict users' ratings on items and suggest certain items to users that they were most likely to be interested in. However, their scope was restricted to just recommendation as they could not use m-wallet or any other digital platform to make online purchases. They utilized user and item feature information, such as the demographic information of users and genres of movies for performing user ratings. Individual preferences were estimated and grouped over users and items to check for similar individuals that are close in nature. Computationally, they designed an algorithm applying the convex method and the alternating direction method of multipliers to deal with the nonconvexity of the loss function and the fusion type penalty respectively. Theoretical rate of convergence was investigated for our new method. We also showed theoretically that incorporating the correlation structure gave higher asymptotic importance of the estimators compared to ignoring it.

\subsection{Algorithm of the Existing System}

Step 1: Start

Step 2: Declare all variables

Step 3: RD, L, UN, PW, RFP, PO, QS,

MLT, OFS, FPSB Where RD is Registration Details, $\mathrm{L}$ is login, $\mathrm{UN}$ is

Username, PW is Password, RFP is recommended fashion product, PO is Purchase Order, MLT is Machine

Learning Technique, OFS is Organized Fashion Store, FPSB is Fashion Product Search Bar and QS is Quit System

Step 4: Initiate L

Step 5: $\mathrm{L}=\mathrm{UN}+\mathrm{PW}$

Step 6: Activate MLT and enter OFS

Step 7: Input details for FPSB

Step 8: Launch RFP

Step 9: Activate PO

Step 10: Enter PO details and make payment transaction

Step 11: Proceed to QS

Step 12: Stop 


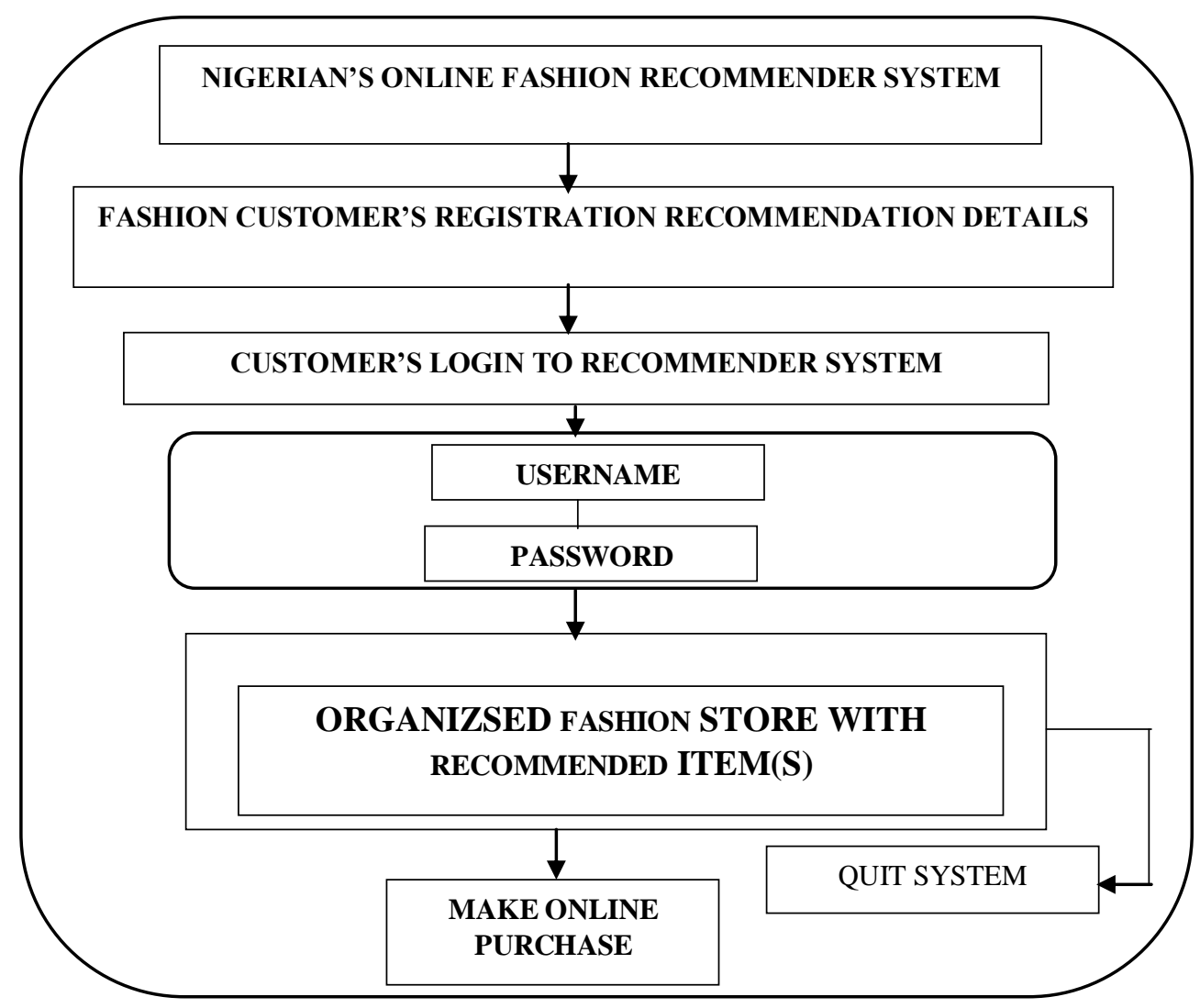

Figure 2: An Organized Fashion Recommender System: Existing System Architecture (Source: Onuodu \&Ajaba [21])

\subsection{Disadvantages of the Existing System}

i. Unavailability of secure payment platform for online purchase.

ii. Lack of a user-friendly interface that can be operated by even computer novice(s).

iii. Lack of trust policy to boost user(s) confidence in using the system.

\subsection{Architecture of the Proposed System}

The proposed system is an enhancement of the existing system. The main aim is to fix the lapse(s) discovered in the existing system. Our proposed system is a regular online shopping system, however, the introduction of the Mobile Wallet (MWallet) adds a new taste to the customer experience of the users of the site. Our system addresses security, integrity, availability and confidentiality of user information and transaction.

The M-Wallet system is designed as a mobile application and also which can also run on the PCs and other devices. It is an online system because it is used to interface with an online platform and the users are online too. The M-Wallet is registered with the online e-commerce / online shopping system in order for it to be used automatic payment option. This guarantees safety and trust. The user's credit card details are stored in the M-Wallet. Money (in any currency) is also loaded into the MWallet software which will be used to pay for the products without having to access their bank account everytime.

The online shopping system contains products grouped under different categories in order to enable easy navigation around the system by even non-tech-savvy individuals. A user-friendly interface is also developed for the users of the system. This will make visiting the online shop interesting and fun to visit even when no purchase is intended and will also boost recommendations by other users. The system is always available both at night and transactions can be carried out at any time. The products displayed on the online shop are also verifiable, i.e. fake or non-existing products are not displayed on the shop. There is also a refund policy for products which do not meet the user's expectation. This demonstrates integrity. Confidentiality is guaranteed by encrypting the user's password and pins using MD5 encryption algorithm to avoid malicious access. 


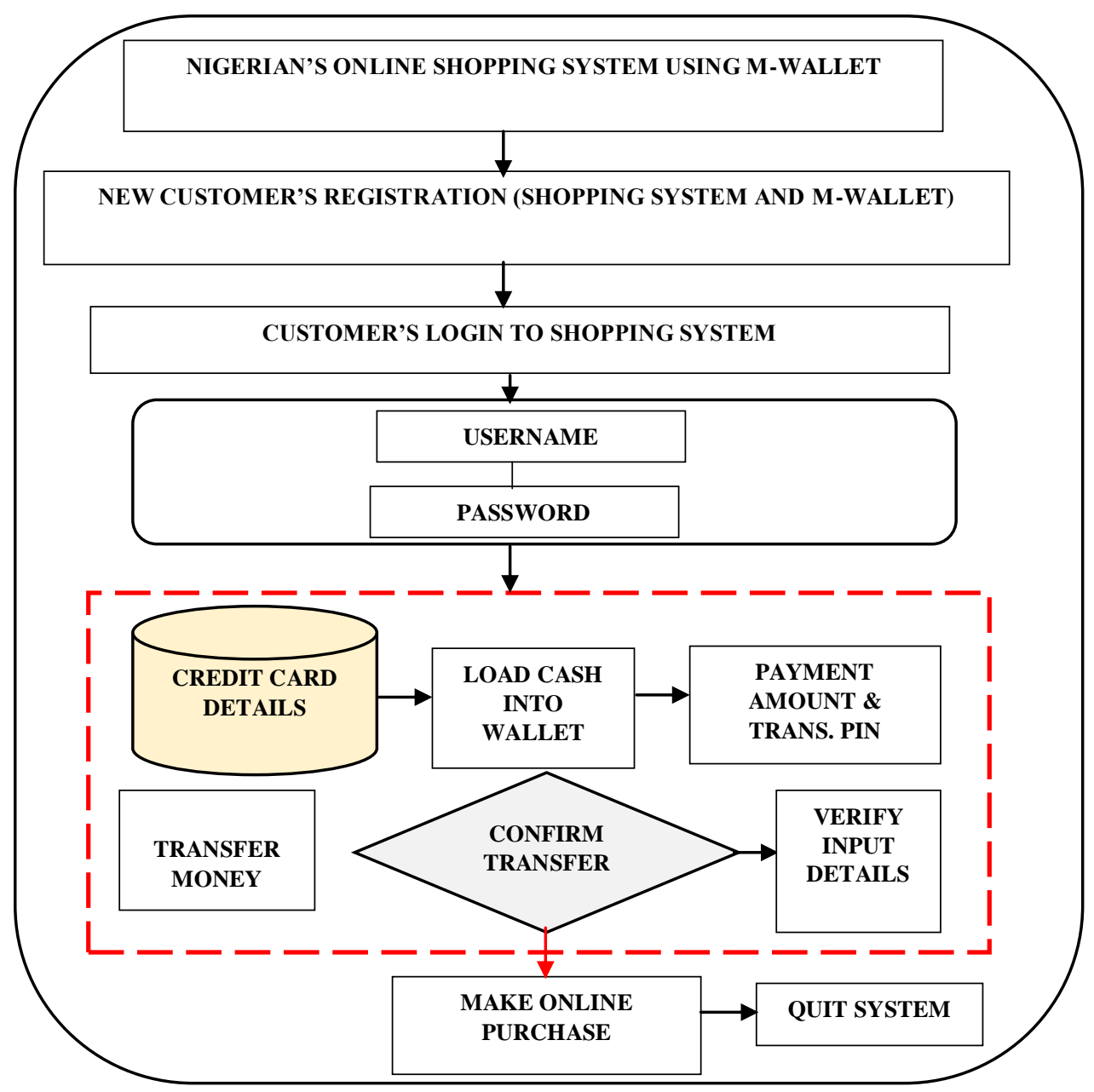

Figure 3: An Enhanced Online Shopping System using M-Wallet: Proposed System

\subsection{Algorithm of the Proposed System}

Step 1: Start

Step 2: Declare all variables

Step 3: CRD, LOS, UN, PW, RFP, PO, QS, C, TC, TP, MLT, OFS, MW, LC, FPSB, CP, VID, L Where CRD is Card Registration Details, LOS is Launch Online Shop, UN is Username, PW is Password, OSP is Online Shop product, $\mathrm{PO}$ is Purchase Order, LC is Load Cash, L is Login, MW is M-Wallet, CP is Confirm Payment, VID is Verify Input details, Cash, Transfer Pin, Transfer Pin, MOP is Make online Purchaseand QS is Quit System

Step 4: Initiate LOS

Step 5: Initiate L for OS

Step 6: $\mathrm{L}=\mathrm{UN}+\mathrm{PW}$

Step 7: View OSP

Step 8: Initiate PO.

Step 9: Load MW

$$
\mathrm{MW}=\mathrm{C}+\mathrm{CRD}
$$

Step 10: Initiate Payment
Step 11: CP

$$
\text { Payment }=\mathrm{TC}+\mathrm{TP}
$$

MOP

$$
\text { IF CP }=\text { True }
$$

Step 12: Proceed to QS

Step 13: Else Initiate VID.

Step 14: Stop

\subsection{Advantages of the Proposed System}

i. The proposed system provided for fast, easy and exciting shopping online experience.

ii. There is a secure and efficient payment platform that provides integrity, confidentiality and availability.

iii. The setup of the transaction process is user-friendly.

iv. Diversity and awareness of available products are made available by the online store. 


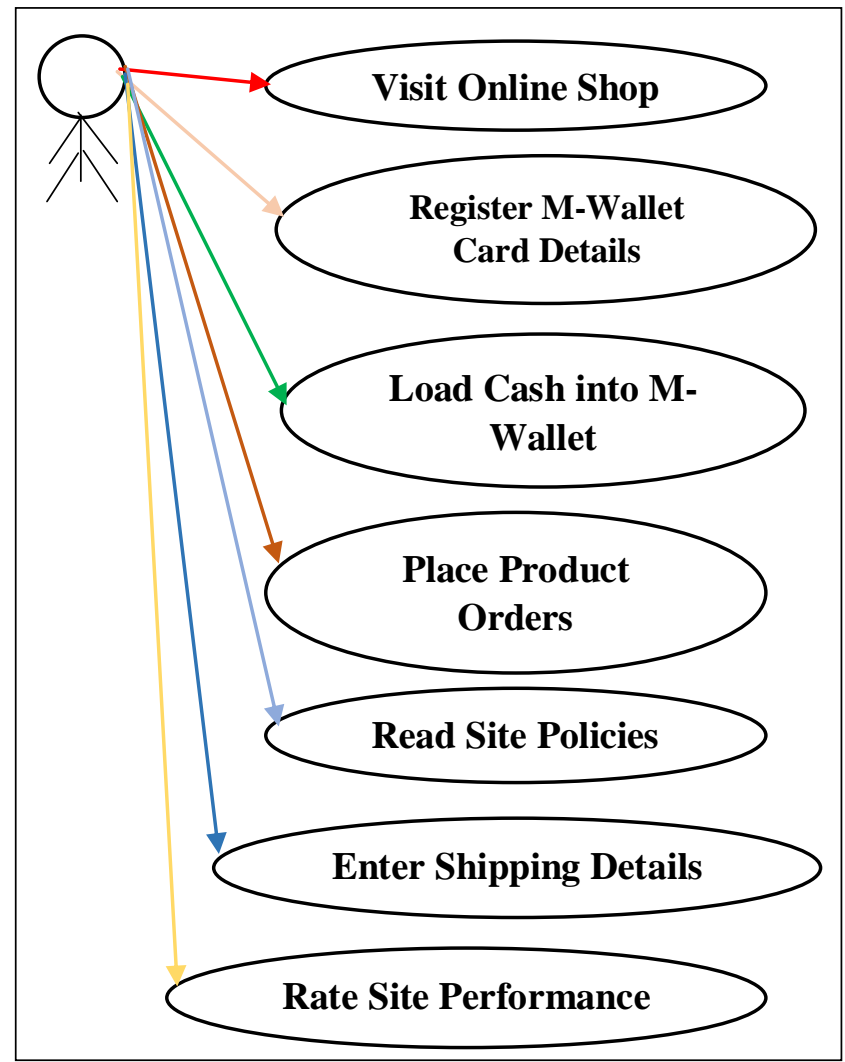

Figure 4: Use case Diagram of the Proposed System

\section{RESULTS AND DISCUSSIONS}

Our system was implemented using PHP as programming language and MySQL as database. The system contains menus which are used to group the available products (clothes, bags, accessories, etc. also according to gender) for easy navigation. This promote user-friendliness. If an online shopping store requires specific computing skills making it difficult to navigate by the "lay man" then the site will lose clients. This is the idea behind the design of our system. Anyone who can operate a mobile phone can also navigate through this system.

When a user wants to place an order, he/she would have to sign up to the system first. However, for a regular visit who just wants to track available products, prices and other information, they can do that without any form of registration. The purpose of the registration is to capture the location, quantity of products and payment options that the buyer wants to explore. It is also aimed at keeping stock of the products that customers are requesting for or buying the most, user behavior can also be derived from the registration details.

The products that the users are interested in are added are added to the cart until all the choices are made and then the user proceeds to the payment page.

The user registers her financial information on the first use of the M-Wallet. The credit card details, the last four digits of the card number, the expiry date of the card and the card's pin are some of the data required for the registration (see fig. 8).

After this initial registration, the user can subsequently use the M-Wallet platform to buy things from the online store without having physical cash. The registration information are also stored in the database to avoid re-registration every time. 


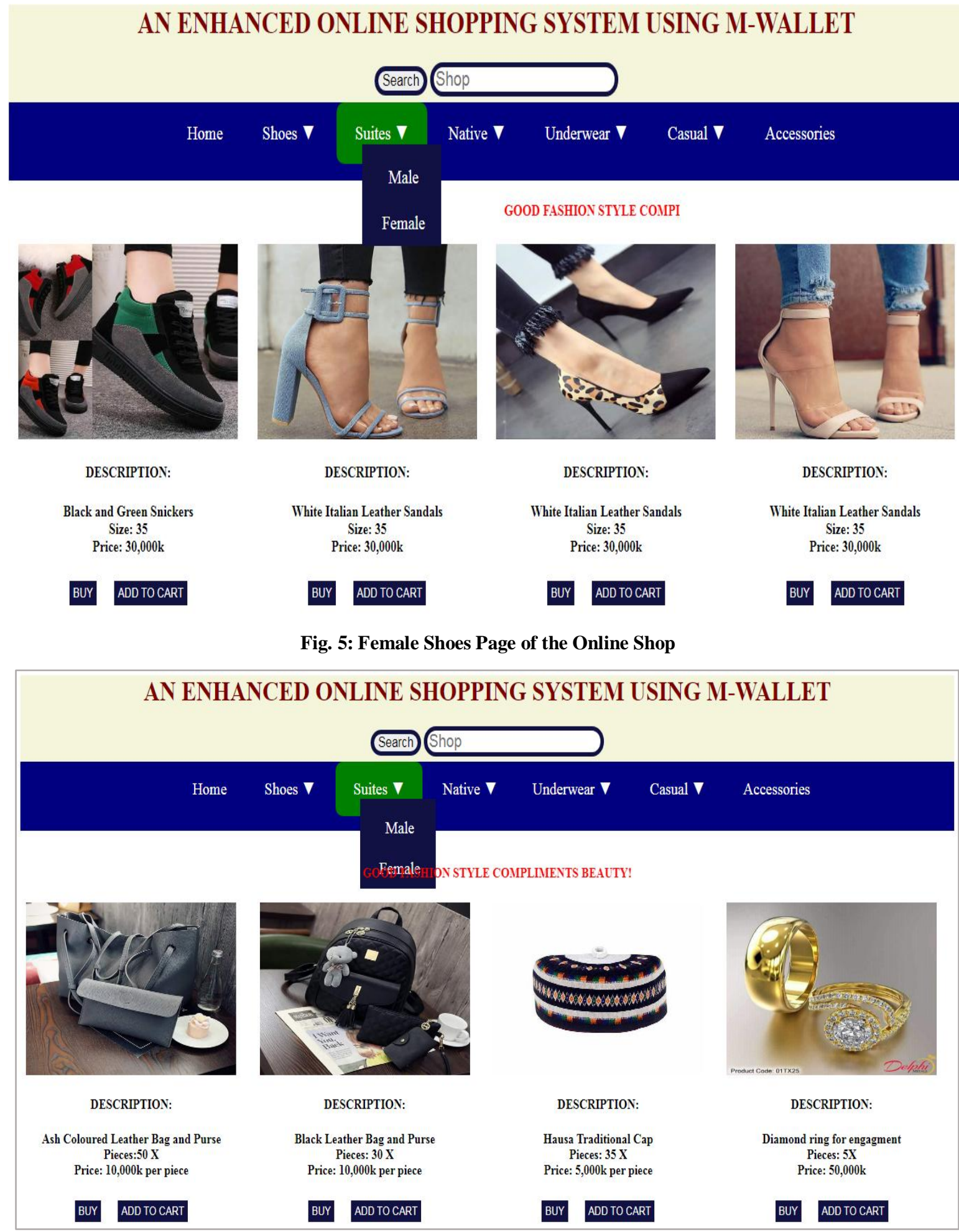

Fig. 6: Accessory Page of the Online Shop 

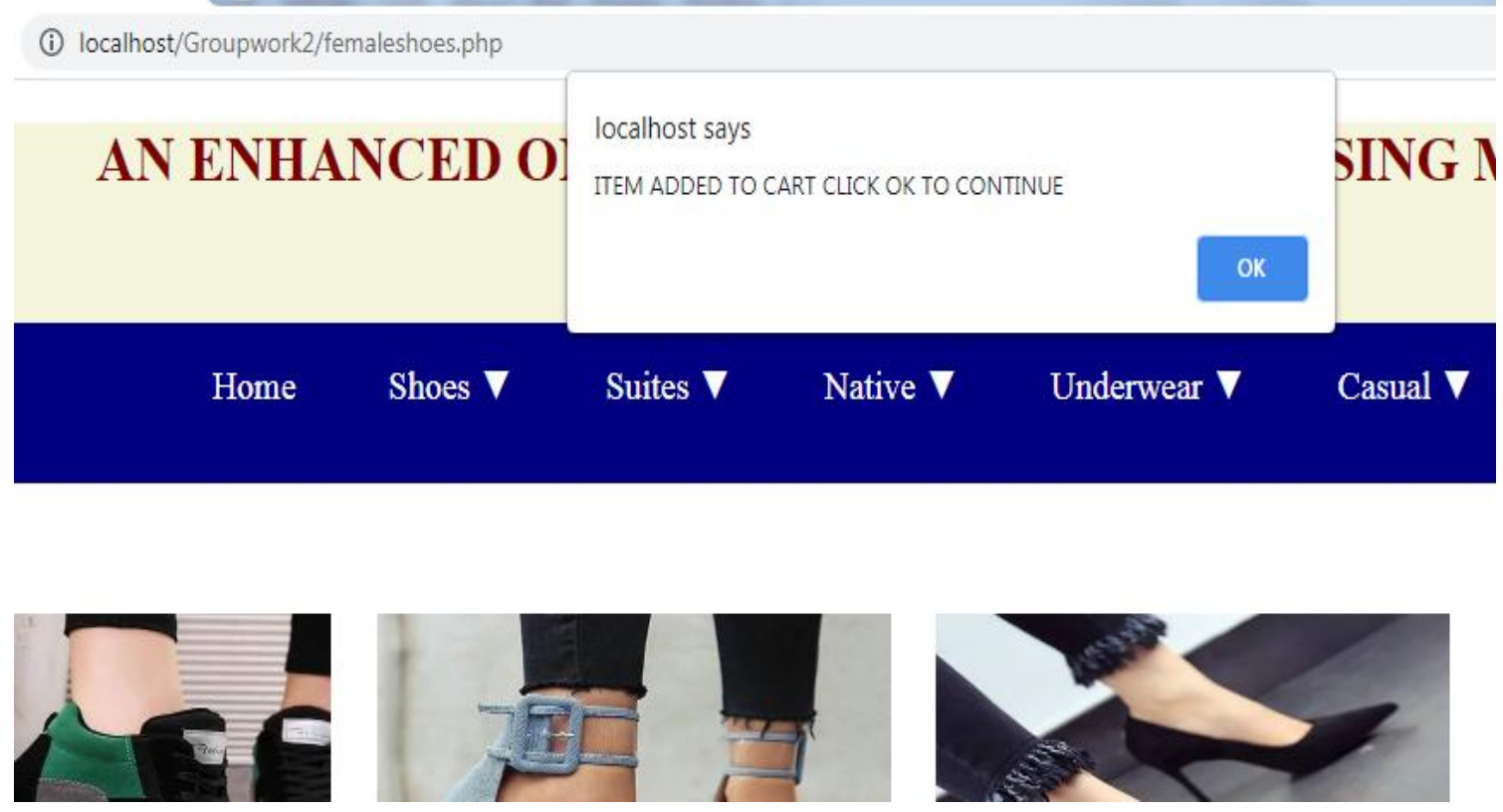

Fig. 7: Item Added to Cart Alert

M-WALLET SYSTEM

\section{CREDIT CARD REGISTRATION PAGE}

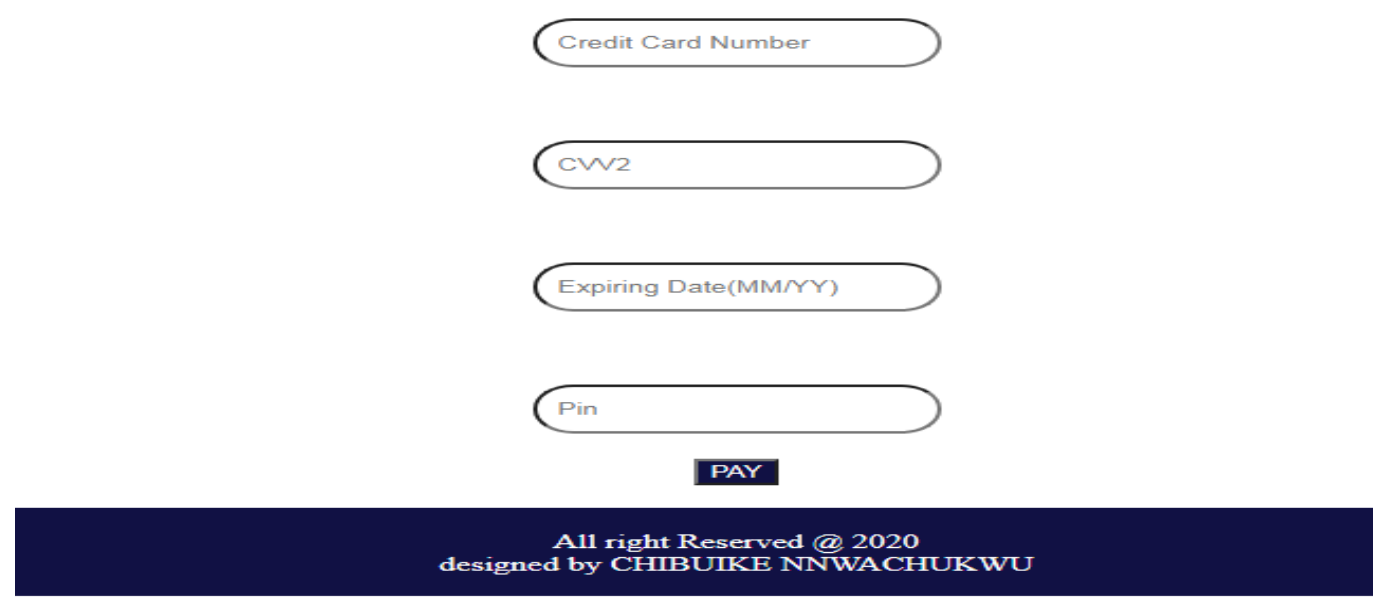

Fig. 8: Credit Card Registration Page 


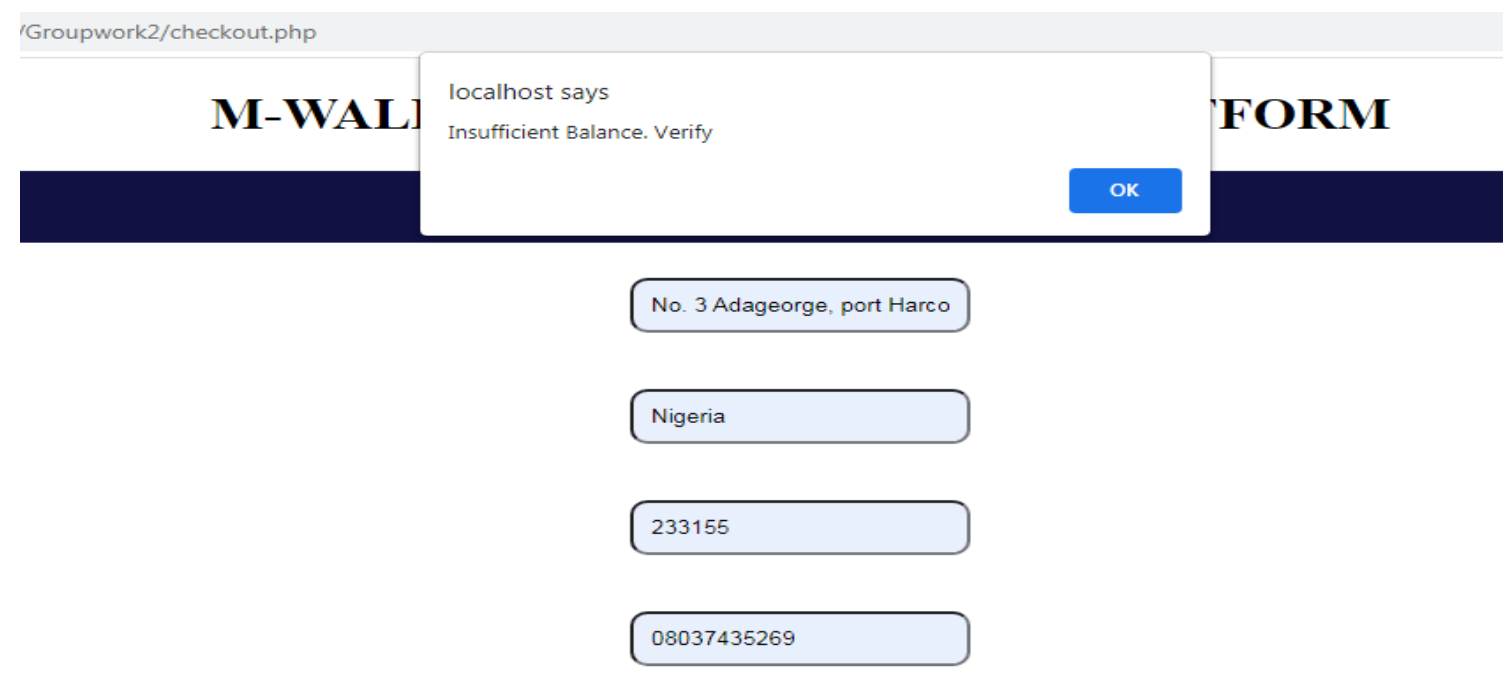

\section{Payment}

Payment Options: Select Payment Option $\backsim$

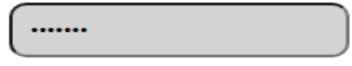

BUY

Fig. 9: M-Wallet Payment Platform Alert

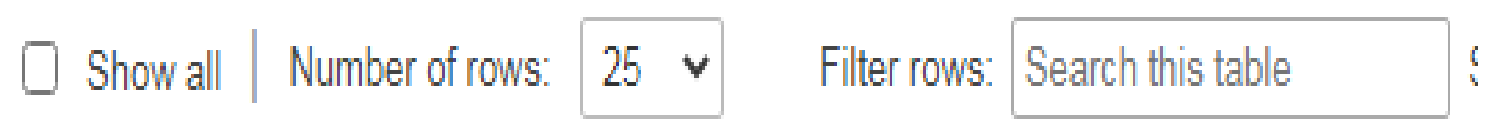

\section{- Options \\ $\leftarrow T \rightarrow \quad \quad \nabla$ ID Credit_Number CWV2 Expiry Date Pin

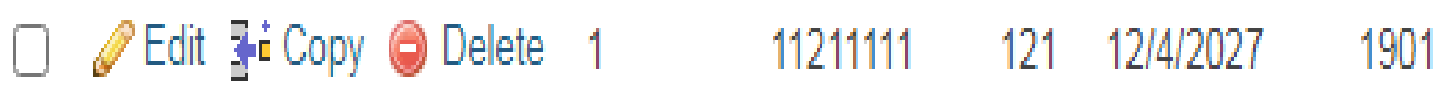

C D Edit 率 Copy $\odot$ Delete $2 \quad 423533622 \quad 223 \quad 13 / 1222024 \quad 1324$

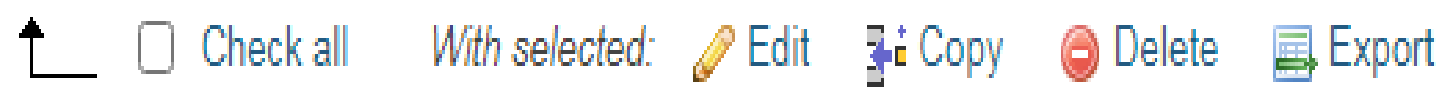

Fig. 10: Card Registration Details

After launching the M-Wallet payment platform and entering the required information including the purchase order information, the money is transferred to the online vendor and the goods are scheduled for shipping to the customer's location within 24 hours. The contact details of the online vendors are displayed on the page so that, reports, suggestions, complaints etc. can be filed when the product is delivered or not.

If the transfer to the vendor is unsuccessful, there will be an alert on the customer's screen indicating the cause of the failure. At this point the client verifies his transaction details or confirms his balance is enough for the transaction (see fig. 9).

\section{PERFORMANCE EVALUATION}

To ascertain the performance of our proposed system we carried out an analysis using certain parameters such as time and cost complexities, cross platform adaptability, response time etc. Table 1 displays the performance values for each parameter. From the evaluation of the system, the total performance of the proposed system was gotten as $40 \%$, while the existing system performance was gotten to be $26 \%$. Time complexity and model efficiency of the proposed system was higher than that of the existing system. 
Table 1: Performance Evaluation Table

\begin{tabular}{|c|c|c|c|c|}
\hline S/N & Parameter & $\begin{array}{c}\text { Existing } \\
\text { Model }\end{array}$ & $\begin{array}{c}\text { Proposed } \\
\text { Model }\end{array}$ & Parameter \\
\hline 1 & $\begin{array}{c}\text { Time } \\
\text { Complexity } \\
\text { (TC) }\end{array}$ & $\begin{array}{c}10 \\
\text { Seconds }\end{array}$ & $\begin{array}{c}3 \\
\text { Seconds }\end{array}$ & $\begin{array}{c}\text { Time } \\
\text { Complexity } \\
\text { (TC) }\end{array}$ \\
\hline 2 & $\begin{array}{c}\text { Bench } \\
\text { Mark (BM) }\end{array}$ & 5.0 & 5.0 & $\begin{array}{c}\text { Bench } \\
\text { Mark (BM) }\end{array}$ \\
\hline 3 & $\begin{array}{c}\text { Cross } \\
\text { Platform } \\
\text { Adaptabilit } \\
\text { y (CPA) }\end{array}$ & 1.0 & 5.0 & $\begin{array}{c}\text { Cross } \\
\text { Platform } \\
\text { Adaptabilit } \\
\text { y (CPA) }\end{array}$ \\
\hline 4 & $\begin{array}{c}\text { Cost } \\
\text { Efficiency } \\
\text { (CE) }\end{array}$ & 5.0 & 10.0 & $\begin{array}{c}\text { Cost } \\
\text { Efficiency } \\
\text { (CE) }\end{array}$ \\
\hline 5 & $\begin{array}{c}\text { Processing } \\
\text { Speed (PS) }\end{array}$ & 5.0 & 10.0 & $\begin{array}{c}\text { Processing } \\
\text { Speed (PS) }\end{array}$ \\
\hline 6 & $\begin{array}{c}\text { GUI } \\
\text { Friendlines } \\
\text { s (GF) }\end{array}$ & 5.0 & 7.0 & $\begin{array}{c}\text { GUI } \\
\text { Friendliness } \\
\text { (GF) }\end{array}$ \\
\hline
\end{tabular}

Total Performance Score $=\sum$ Parameters

\section{Error Rate}

Existing System $=5+5.0+1.0+5.0+5.0+5.0+5.0$

$$
=26 \%
$$

Proposed System $=3+5+5+10+10+7$

$$
=40 \%
$$

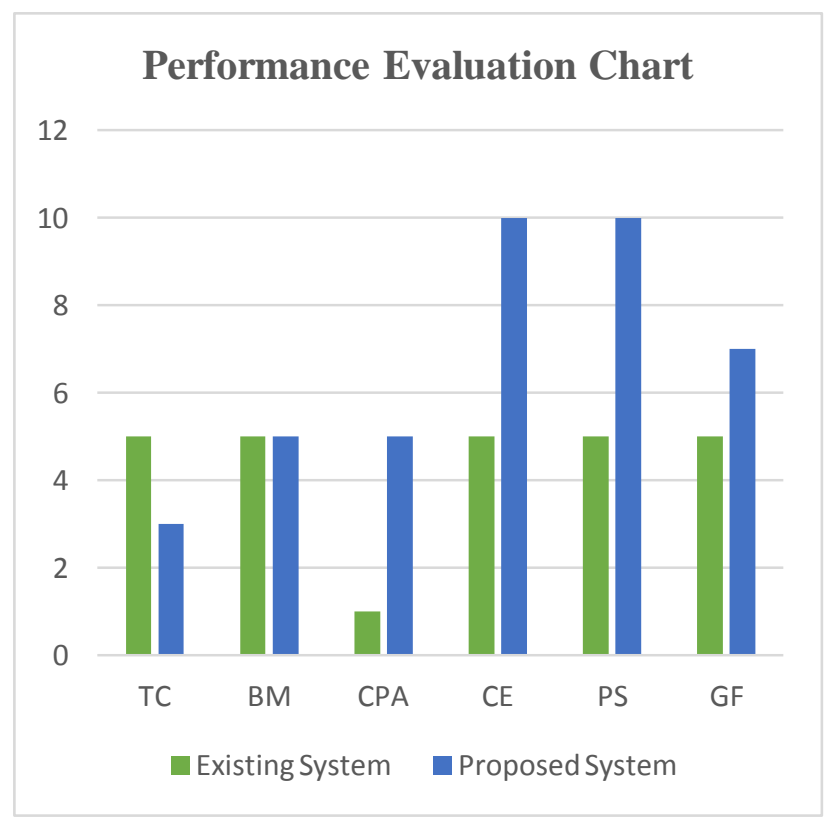

\section{CONCLUSION}

The advent of the Internet has transformed the way things are done in various sectors. Commerce or simply put buying and selling is one of the sectors that the internet has affected. An online shopping system is an online platform where products are displayed for sale. An M-Wallet was simulated as a digital payment system attached to the online shopping system for secure and efficient transaction while using this system. The system was designed to make shopping a fun experience and removed the stress and insecurities involved in physical shopping system. The system outperformed other e-commerce systems due to the integration of the M-Wallet system.

\subsection{Contribution to Knowledge}

An enhanced e-shopping system using M-Wallet has been presented and simulated in this study which is different from other solutions which were previously proposed.

\subsection{Future Scope}

Our future scope would be directed towards deploying the online shopping system online and the development of an Android and Apple based M-Wallet system that can run on smart phones too.

\section{REFERENCES}

[1] Ameh.A. E.2018Design and Implementation of a Wedbased Shopping Management System,B.ScThesis, Godfrey Okoye University, Enugu State, Nigeria. 1-51.

[2] https://en.wikipedia.org/wiki/Digital_wallet.Retrieved $21^{\text {st }}$, April 2021.

[3] Zhao H. and S. Muftic.2012Design and Implementation of a Mobile Transactions Client System: Secure UICC Mobile Wallet." International Journal for Information Security Research (IJISR), 2(1), . 113-140.

[4] Osakwe, C. N. and T. C. Okeke.2016 Facilitating mCommerce growth in Nigeria through m-Money usage: A preliminary analysis. Interdisciplinary Journal of Information, Knowledge, and Management. 11, .115-139.

[5] HassanA., Z. Shukur, M. K. HAsan and A. S. Alkhaleefa.2020 AReview on Electronic Security. Symmetry. 12(1344). 1-24..

[6] IsaacG., S. Meacham, H. Hamzeh, A. Stefanidis and K. Phalp.2018 An Adaptive E-commerce Application using Web Framework Technology and Machine Learning.. 1-10.

[7] BakarN. A, S. Rosbi and K. Uzaki. 2020E-Wallet Transactional Framework for Digital Economy: A Perspective from Islamic Financial Engineering.International Journal of Management Science and Business Administration.6(3), 50-57.

[8] Zheng, S. W. Zheng and X. Jin. . 2015An Intelligent Recommendation System based on Customer Segmentation.'International Journal of Research in Business Studies and Management. 2(11),8-90.

[9] Zulaikha, E. L. Lydia, K. Shankar, Gunardi, and A. Wahyudi. 2019An Integrated Management System for Online Shopping Portals.Journal of Critical Reviews. 6(5). 128-132..

[10] K. W. Hassan, T. S. Kar, A. Hissain, M. M. A. Hashem. 2019 A Fuzzy Logic Based Certain Trust Model for Ecommerce. 1-6.

[11] JunadiS and SFrenrianto. 2015 A Model of Factors Influencing Consumer's Intention to Use E-payment System in Indonesia. Elsevier 59. 214-220. .

[12] Z. Wu and H. Wu. 2017 An Agent-based Fuzzy Recommendation System using Shoppers' Preference for E-commerce Application. International Journal of Uncertainty, Fuzziness and Knowledge-based System. 18(4). 471-497.

[13] VatrapuS. R.. "Design and Implementation of E-commerce Site for Online Shopping.” M.Sc. Project, Governor's State 
University. 1-44

[14] EffiongM. P..2017 Design and Implementation of Online Shopping System. HND Thesis in Computer Science, Uyo City Polytechnic, Uyo, Akwalbom State, Nigeria. . 1-47. JUL. 2017.

[15] Wei F. and Q. Zhang. 2018 Design and Implementation of Online Shopping System based on B/S Model.'MATEC Web of Conferences. 246. 1-5.

[16] AmcaH. and E. Celebi. 2009 Design and Application of Mobile Payment System with Embedded Systems and Service oriented Architecture. 1-6.

[17] Karim W., A. Haque, M.A. Ulfy, A. Hossain and Z. Anis. 2020 Factorsinfluencingthe use of E-Wallet as a Payment Method among Malaysian Young Adults."Journal of
International Business and Management (JIBM). 3,(2). 112.

[18] Pramsane S. 2005 Design and Implementation of online Shopping Center." Proceedings of the International Conference on Computer and Industrial Management, ICIM, 29-30, Bangkok, Thailand. 1-6.

[19] UnadkatR. and M. Barot. 2017 Survey Paper on Fuzzy Logic Based Recommender System.IJARIIE. 3(1). 52-63.

[20] HassanA., Z. Shukur, M. Hasan and A. S. Al-Khaleefa. 2020 A Review on Electronic Payment Security.Symmetry. 12(1344). 1-24. 2020. Doi: 10.3390/sym12081344.

[21] Onuodu F. E. and F. E. Ajaba.An Organized Recommender System for Nigerian Fashion using Machine Learning." 